\title{
Recently characterized soft tissue tumors that bring biologic insight
}

\author{
Christopher D M Fletcher \\ Department of Pathology, Brigham and Women's Hospital and Harvard Medical School, Boston, \\ MA, USA
}

\begin{abstract}
Previously unrecognized but clinicopathologically (and often molecularly) distinct types of soft tissue tumor continue to be characterized, allowing wider recognition, more consistent application of diagnostic criteria, more reliable prediction of tumor behavior and enhancement of existing classification schemes. Examples of such 'entities' that have become much better understood over the past decade or so include deep 'benign' fibrous histiocytoma, hemosiderotic fibrolipomatous tumor, PEComa, spindle cell liposarcoma, myoepithelial tumors of soft tissue and spindle cell/sclerosing rhabdomyosarcoma. These tumor types, as well as the insights which they have engendered, are briefly reviewed here.
\end{abstract}

Modern Pathology (2014) 27, S98-S112; doi:10.1038/modpathol.2013.172

Keywords: benign; sarcoma; soft tissue; tumor

In the last two decades, a large number of 'new entities' within the group of soft tissue tumors have been described in the literature. Strictly speaking, most new entities are not really 'new', but represent uncommon lesions with reproducible morphological criteria, which previously went unrecognized or undescribed, but which have gradually been collected and analyzed over the years, especially in referral centers. Some pathologists consider that the description of so-called 'new entities' only splits unnecessarily an already difficult group of lesions. Although, from the academic point of view, there is no doubt about the benefit of characterizing newly recognized entities, its main value should be in clinical practice. The principal importance (and value) of the characterization of any tumor type is that it allows reproducible separation of lesions with different clinical behavior and prognosis and therefore facilitates rational planning of treatment. Furthermore, it may help to clarify confusion and controversy at the scientific or molecular level-as witness the more orderly approach to polyphenotypic small cell neoplasms following delineation of the desmoplastic small round cell tumor some years ago. In 'real life', the relevance of continual refinement of tumor classification is exemplified

Correspondence: Dr CDM Fletcher, MD, FRCPath, Department of Pathology, Brigham and Women's Hospital and Harvard Medical School, 75 Francis Street, Boston, MA 02115, USA.

E-mail: cfletcher@partners.org

Received 13 June 2013; accepted 13 June 2013 by noting, for example, that almost all cases of retiform hemangioendothelioma were formerly mislabeled angiosarcoma, chondroid lipomas were frequently misdiagnosed as sarcoma and, conversely, low-grade fibromyxoid sarcoma was (and often still is) largely underrecognized and is often misclassified as a benign fibrous neoplasm. It is therefore the purpose of this overview to review some of the more recently characterized soft tissue neoplasms and to emphasize the benefits of their accurate recognition, focussing on those which bring (at least potentially) important biological or conceptual insights.

\section{Deep 'benign' fibrous histiocytoma}

A small proportion $(<5 \%)$ of benign fibrous histiocytomas arise entirely within subcutaneous tissue, skeletal muscle or within the abdominal cavity. ${ }^{1,2}$ Because of their deeper location, these tumors are often mislabelled as malignant. Definitionally, they lack dermal involvement. Such tumors affect principally adults in middle age, although the overall age range is wide, and there is a predominance in males. The lower limb and the head and neck region are the commonest sites and most cases measure $4 \mathrm{~cm}$ or less in diameter. Up to $25-30 \%$ of tumors recur locally, especially if marginally or incompletely excised. Rare lesions may metastasize.

In contrast to their more common cutaneous counterparts, more deeply located fibrous histiocytomas 
a

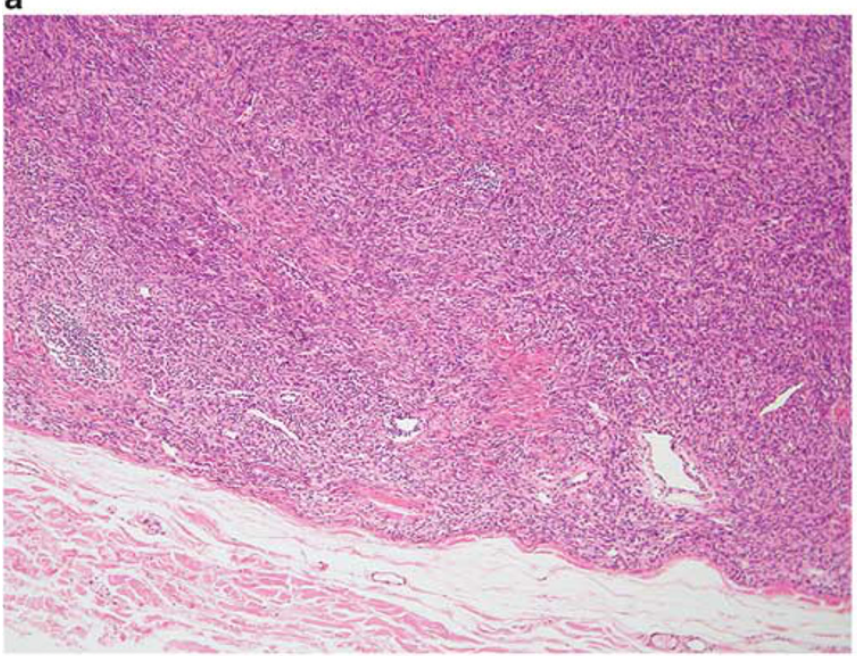

c

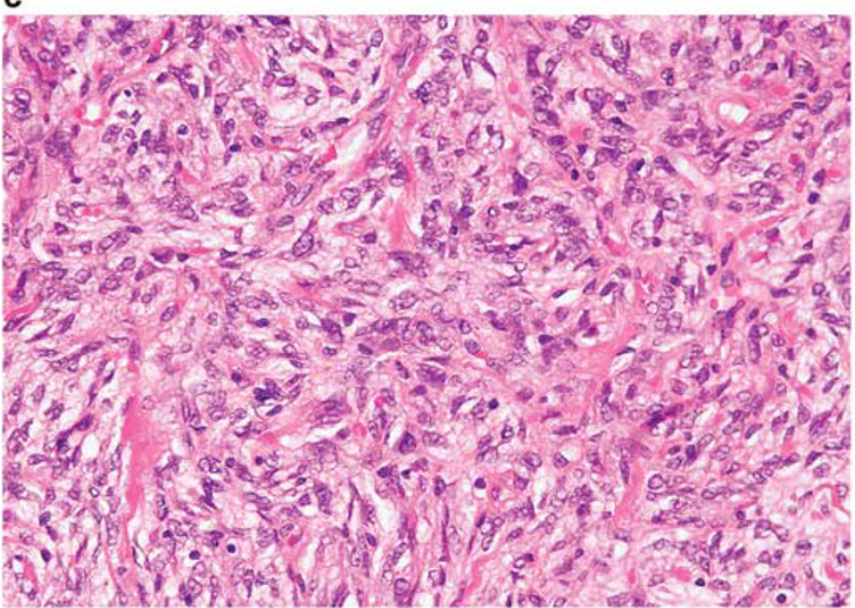

b

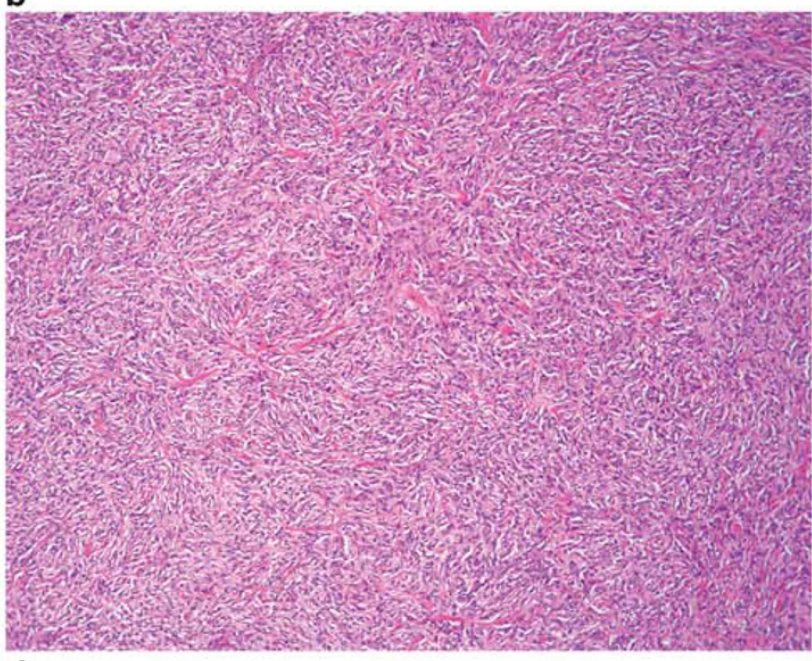

d

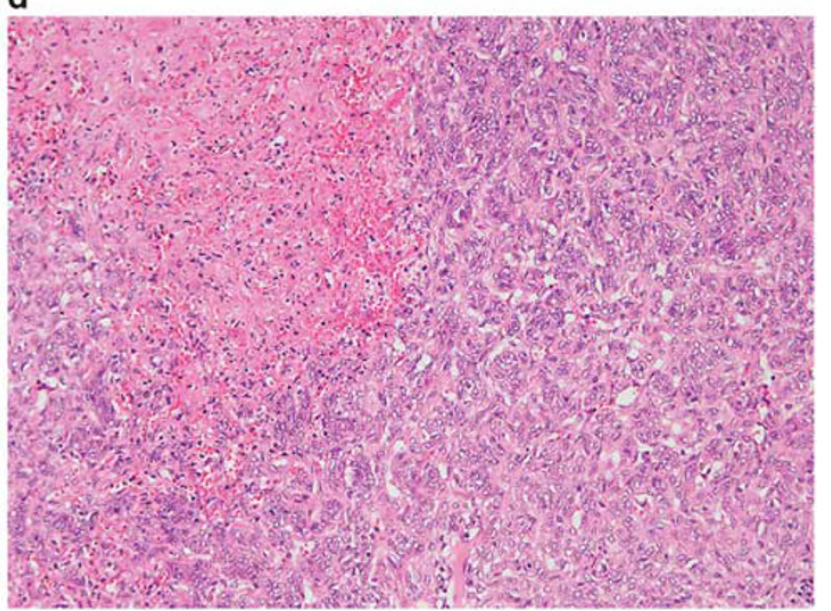

Figure 1 Deep benign fibrous histiocytoma. Note the well-circumscribed margin (a; top left). These lesions usually show only limited cytological polymorphism and a well-developed storiform growth pattern (top right; b). Cytomorphology is very similar to that of cellular fibrous histiocytoma in skin (lower left; c). Small foci of necrosis, similar to those seen in cutaneous cellular fibrous histiocytoma, may be present (lower right; d).

tend to be well circumscribed and pseudoencapsulated (Figure 1a). Central hemorrhage or cystic change is an occasional feature. The other principal difference from cutaneous lesions is that usually there is less cytologic polymorphism (Figure 1b) and most cases consist largely of eosinophilic spindle cells with elongated or plump vesicular nuclei, arranged in a storiform pattern, admixed with a small number of lymphocytes, thereby resembling cellular FH (Figure 1c). Foamy histiocytes and giant cells are usually infrequent. Mitoses are commonly present but typically number $<5$ per 10 high power fields and small foci of necrosis are sometimes found (Figure 1d). A further pseudomalignant feature is the very occasional finding of vascular invasion, just as may rarely be seen in cutaneous lesions. With regard to the stroma, there may be hyalinization or myxoid change and both perivascular hyalinization or hemangiopericytoma-like vessels are quite frequent.
Immunohistochemistry has no positive role in the diagnosis other than by facilitating the exclusion of some other lesions. Dermatofibrosarcoma is excluded by its superficial location and generally infiltrative margins. CD34 staining is not helpful as, in our experience, deep FH may also show positivity similar to DFSP. Solitary fibrous tumor typically shows greater variation in cellularity and a patternless architecture. The only other real differential diagnosis is so-called 'malignant fibrous histiocytoma' (undifferentiated pleomorphic sarcoma): whatever the latter may be, one would expect to see obvious cytologic atypia and pleomorphism and frequently abnormal mitoses.

\section{Hemosiderotic fibrolipomatous tumor}

Hemosiderotic fibrolipomatous tumor, ${ }^{3}$ known in the past as hemosiderotic fibrohistiocytic lipomatous 

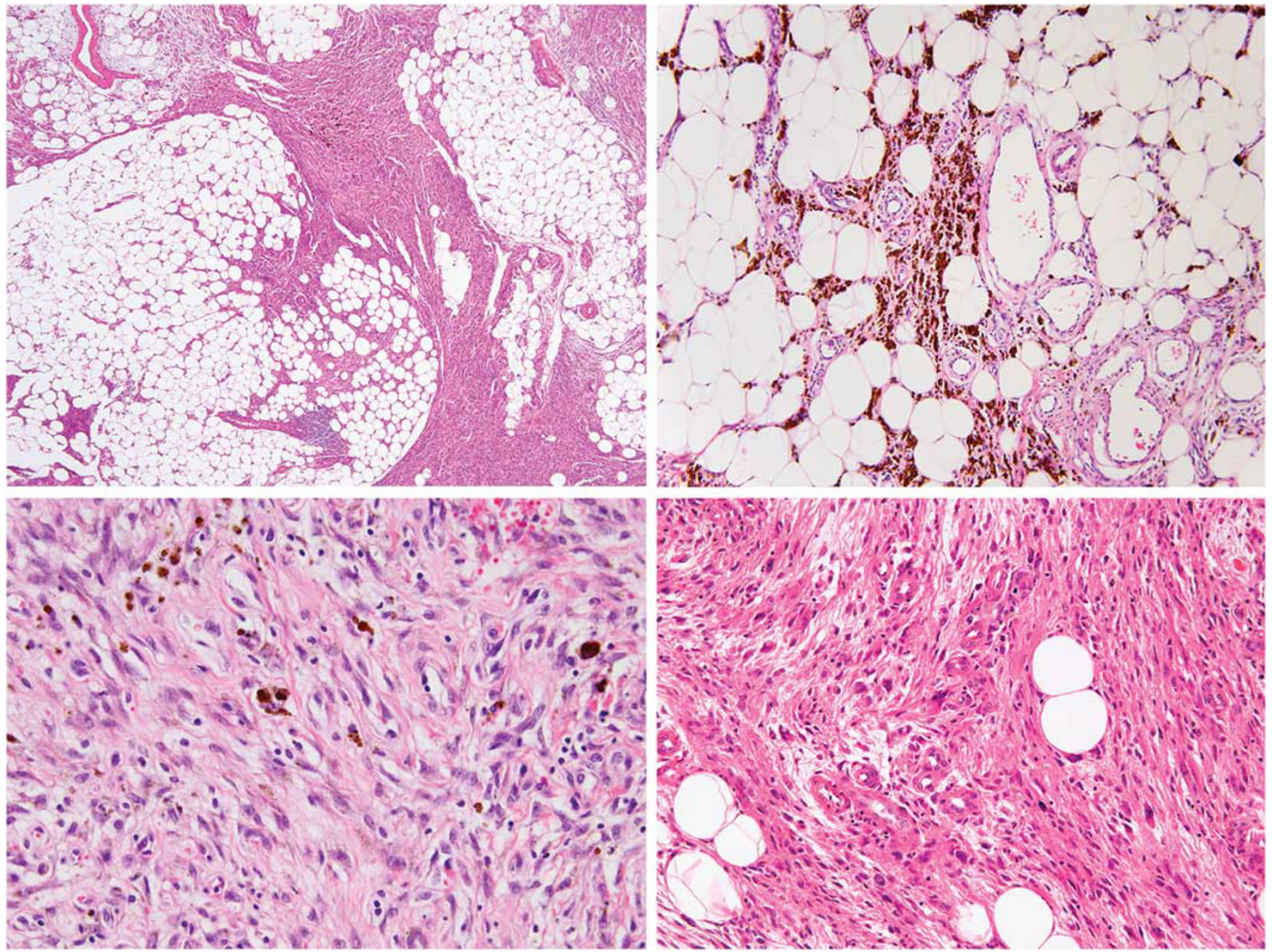

Figure 2 Hemosiderotic fibrolipomatous tumour. These lesions show a complex admixture of the spindle cell and adipocytic components (top left) and multifocally prominent hemosiderin deposition is a consistent feature (top right). Generally these lesions show uniform fibroblastic cytomorphology (lower left), but occasional cases may show nuclear atypia and hyperchromasia (lower right).

lesion, ${ }^{4}$ is an uncommon tumor of uncertain lineage, which arises almost invariably as a mass in the ankle/foot region of adults. Cases in childhood are rare. These lesions may recur (sometimes more than once) but appear not to be destructive. Some authors have proposed that these are precursor lesions for pleomorphic hyalinizing angiectatic tumor, ${ }^{5}$ but this is controversial and not generally accepted.

Histologically (Figure 2), these lesions consist of a complex admixture, in variable proportions of mature adipocytes and uniform fibroblastic spindle cells, the latter dissecting through the fat in fascicles, whorls or in a honeycomb fashion, in association with prominent hemosiderin deposition. The spindle cell component may be accompanied by scattered osteoclastic giant cells. Immunohistochemistry has no useful role in the diagnosis.

Rare cases may show focal nuclear atypia and pleomorphism, the exact biological significance of which is uncertain at present. However, since the publication of our series in 2006, ${ }^{4}$ I have now personally experienced several cases that, during the course of recurrences, have progressed to what can only be described as frank sarcoma. More importantly, I and others have now seen several cases having prominent myxoid areas which are morphologically indistinguishable from myxoinflammatory fibroblastic sarcoma. In this regard, recent cytogenetic data have shown that both hemosiderotic fibrolipomatous tumor as well as myxoinflammatory fibroblastic sarcoma in fact share the exact same chromosomal translocation $\mathrm{t}(1 ; 10)(\mathrm{p} 22 ; \mathrm{q} 24),{ }^{6,7}$ suggesting a very close relationship between these two entities. Our personal experience mirrors these published data and has confirmed the presence of an identical fusion gene, TGFBR3-MGEA5 in both types of lesion. ${ }^{8}$ This molecular genetic abnormality appears not to be present in pleomorphic hyalinizing angiectatic tumor. 8,9 

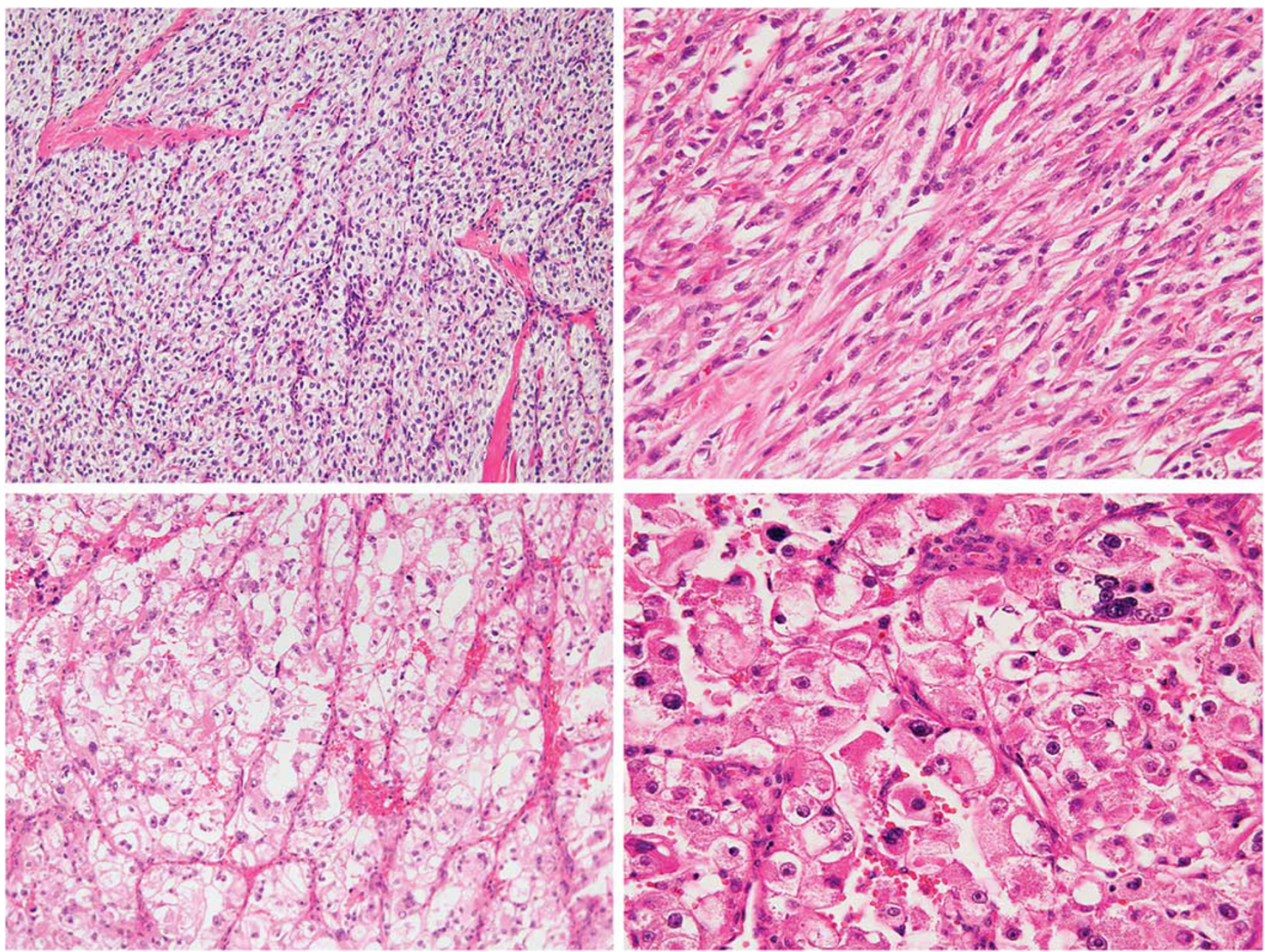

Figure 3 PEComa. These lesions often have a nested architecture with mainly epithelioid cells being separated by delicate thin-walled vascular channels (top left). Some lesions have predominantly spindled morphology with rather granular eosinophilic cytoplasm (top right), while others consist predominantly of clear cells (often mimicking renal cell carcinoma) (lower left). Focal nuclear atypia and pleomorphism in the absence of mitotic activity or necrosis is of uncertain prognostic significance (lower right).

\section{PEComa}

Tumors of perivascular epithelioid cells, now known as PEComas, represent a family of neoplasms, first proposed by Bonetti and Pea, ${ }^{10}$ which are characterized by immunohistochemical evidence of dual myomelanocytic differentiation. ${ }^{11,12}$ Lesions in this general category include angiomyolipoma (and its so-called epithelioid variant), clear cell ('sugar') tumor and lymphangioleiomyomatosis. It has been recognized in recent years that histologically comparable lesions may arise at a wide variety of sites ${ }^{12-14}$ including intraabdominal and somatic soft tissues and a variety of organs, including most notably the uterus and gastrointestinal tract. Most cases arise in adults and there is a very marked predominance in females. A minority of cases are associated with tuberous sclerosis. Although most cases seem to pursue a benign course (although data are relatively limited thus far), there is also a subset (perhaps $10-15 \%$, but this may be exaggerated by consultation bias) with worrisome morphology (see below) that metastasize.

Histologically, aside from the clearly defined subsets mentioned above, PEComas show a considerable range of morphology, being most often nested and epithelioid, but sometimes predominantly spindled and occasionally very pleomorphic, resembling a pleomorphic myogenic sarcoma (Figure 3). Tumor cells generally have granular eosinophilic or clear cytoplasm and vesicular nuclei, sometimes with prominent nucleoli. There is often a prominent thin-walled branching vascular pattern and, at least focally, the neoplastic cells are usually discernibly arranged in a concentric fashion around these vessels (Figure 4a). Some cases may show prominent stromal hyalinization, particularly in the retroperitoneum, and these are known as sclerosing PEComas. ${ }^{15}$ Another distinct subset are PEComas arising in skin, which usually have clear 

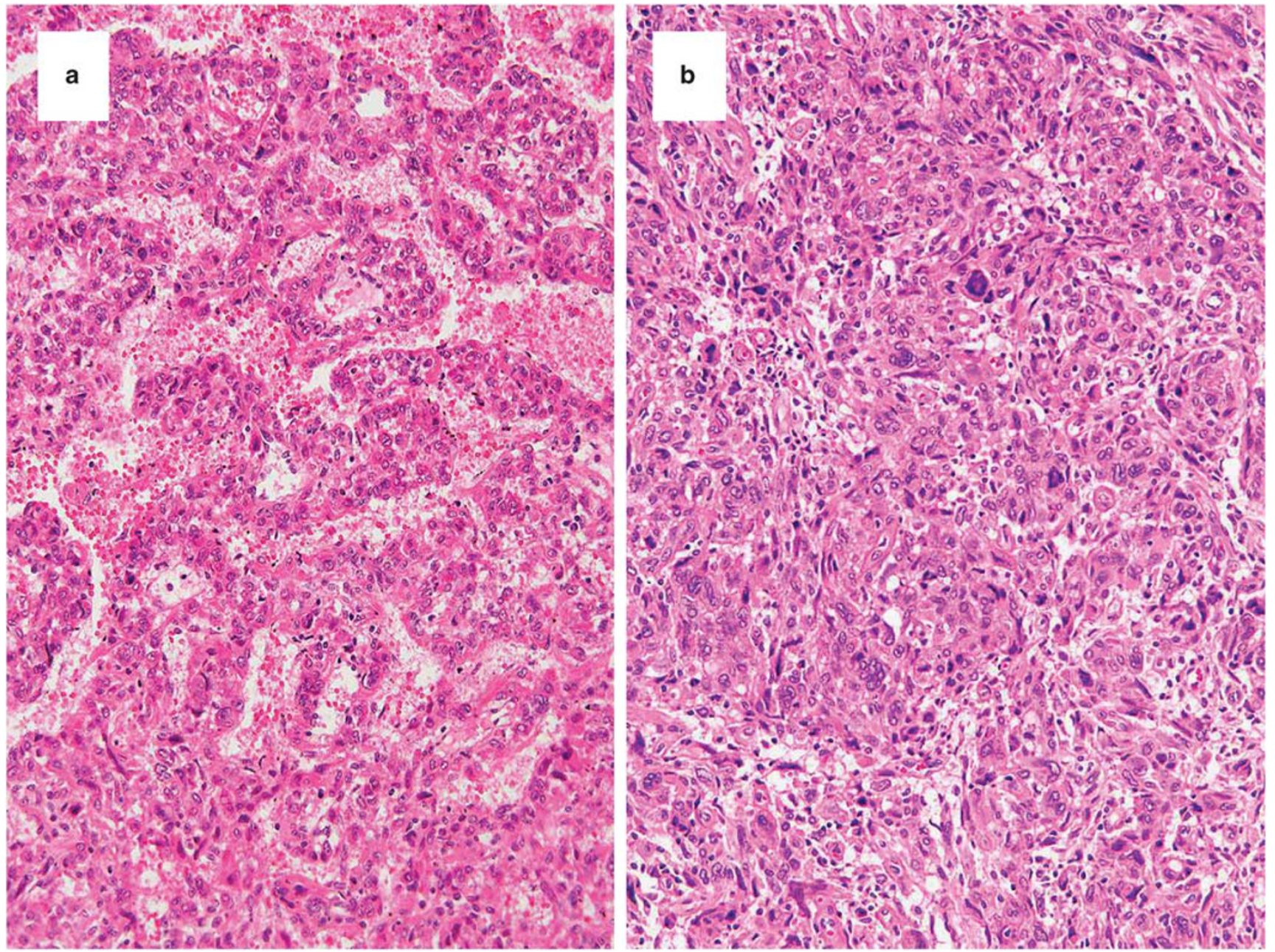

Figure 4 PEComa. Lesional cells are often strikingly arranged in a concentric fashion around vessel walls, with which the cells appear to merge (left; a). Malignant examples of PEComa commonly show diffuse pleomorphism as well as scattered (although typically not numerous) mitotic figures (right; b).

cell morphology ${ }^{16,17}$ (producing potential morphological overlap with balloon cell melanoma or a renal metastasis). The minority of cases which show marked atypia or pleomorphism, readily identified mitotic figures or necrosis are best regarded as malignant (Figure 4b) and personal experience suggests that these lesions are often quite aggressive, with frequently rapid development of metastases. Recurrence is also more frequent in lesions $>5 \mathrm{~cm}^{18}$

Immunohistochemistry has a major role in the diagnosis of these lesions-specifically these tumors usually co-express SMA and HMB-45 (Figure 5), while $>50 \%$ stain for Melan-A and/or MITF (sometimes in the absence of HMB-45) and around 25\% are desmin positive. Recent data suggest that cathepsin $\mathrm{K}$ may also be a useful marker for PEComas. ${ }^{19}$ Interestingly, cutaneous PEComas less consistently stain with myogenic markers. A subset of cases also stain for S-100 protein (allowing possible confusion with melanoma) and for TFE3, the latter being associated with TFE3 gene rearrangement in some cases. ${ }^{20}$ In keeping with the known association between angiomyolipomas, lymphangioleiomyomatosis and some cases of PEComa with tuberous sclerosis, a significant subset of sporadic PEComas show inactivation or loss of TSC2, which, in turn, leads to activation of the mTOR pathway. ${ }^{21,22}$ Interestingly, TSC2 inactivation and TFE3 rearrangement seem to be mutually exclusive. ${ }^{23}$ Recent data indicate that this is of clinical relevance as drugs targeting the mTOR pathway (such as rapamycin, also known as sirolimus) may be effective in palliating patients with metastatic PEComa. ${ }^{24,25}$

\section{Spindle cell liposarcoma}

Spindle cell liposarcoma is a somewhat controversial entity, first described more than 15 years ago, which, until recently, had been thought to represent an unusual variant of atypical lipomatous tumor. ${ }^{26,27}$ These lesions, which are not rare in our 

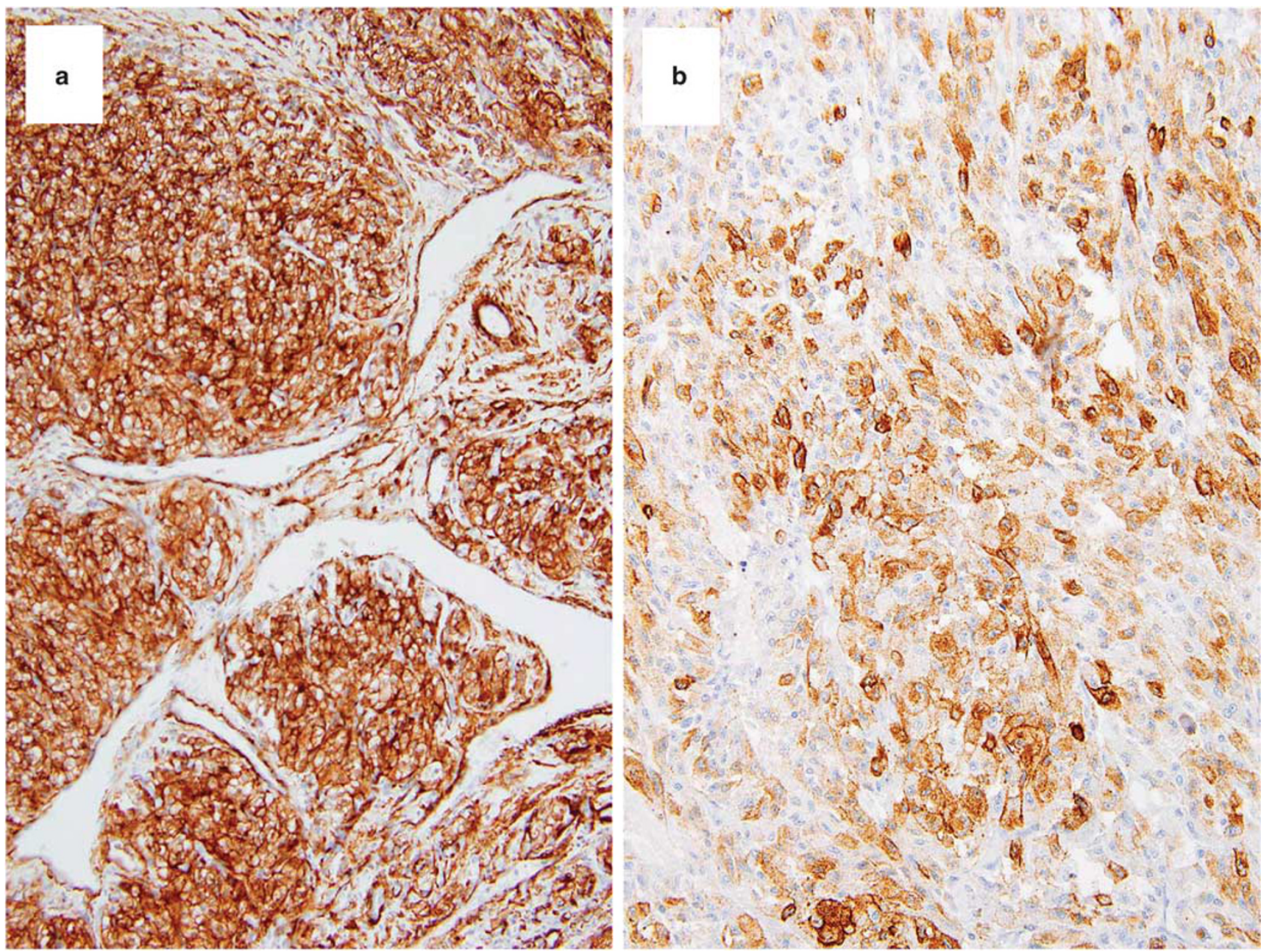

Figure 5 PEComa. These lesions most commonly co-express smooth muscle actin (a) and HMB-45 (b), although expression of either myogenic or melanocytic antigens may often be quite focal in distribution.

experience, occur mostly in adults and show a striking predilection to arise in somatic soft tissue but arise only exceptionally at visceral locations (such as retroperitoneum). Instead, these tumors arise most often in subcutaneous or intramuscular soft tissue of the limbs with the majority of lesions measuring between $5-10 \mathrm{~cm}$. These lesions have an $\sim 15-20 \%$ rate of local recurrence, which may sometimes be repeated but, in contrast to atypical lipomatous tumor/well-differentiated liposarcoma of conventional type, dedifferentiation seems to be exceedingly rare.

These lesions are typically unencapsulated and infiltrative and consist of admixed adipocytic and spindle cell elements in varying proportions (Figure 6). The adipocytes show variation in cell size and may show nuclear atypia or hyperchromasia. Lipoblasts can quite often be identified (Figure 7). The spindle cell component tends to be relatively bland, in some cases resembling conventional spindle cell lipoma and in other cases having almost neural-like morphology with tapering mildly hyperchromatic nuclei. The stroma is variably myxoid or collagenous. Immunostains show positivity for CD34 in around $70 \%$ of cases, S-100 protein positivity in the spindle cell component in 30\% (Figure 8) and desmin positivity in the spindle cell component in $20 \%$. In contrast to conventional atypical lipomatous tumor, staining for MDM2 and CDK4 is most often negative. This latter result is in line with more recent genetic data, ${ }^{28,29}$ which have proposed that these tumors show either monosomy of chromosome 7 or, as suggested by Mentzel et al, ${ }^{16}$ rearrangement of 13q. In our experience, the latter finding seems to be most accurate and this may be further supported by loss of $\mathrm{Rb}$ protein expression (Figure 8). These data suggest that this may prove to be a distinct/separate subtype of liposarcoma.

\section{Myoepithelial tumors of soft tissue}

Myoepithelial lesions arising in non-cutaneous soft tissue have only been characterized quite 

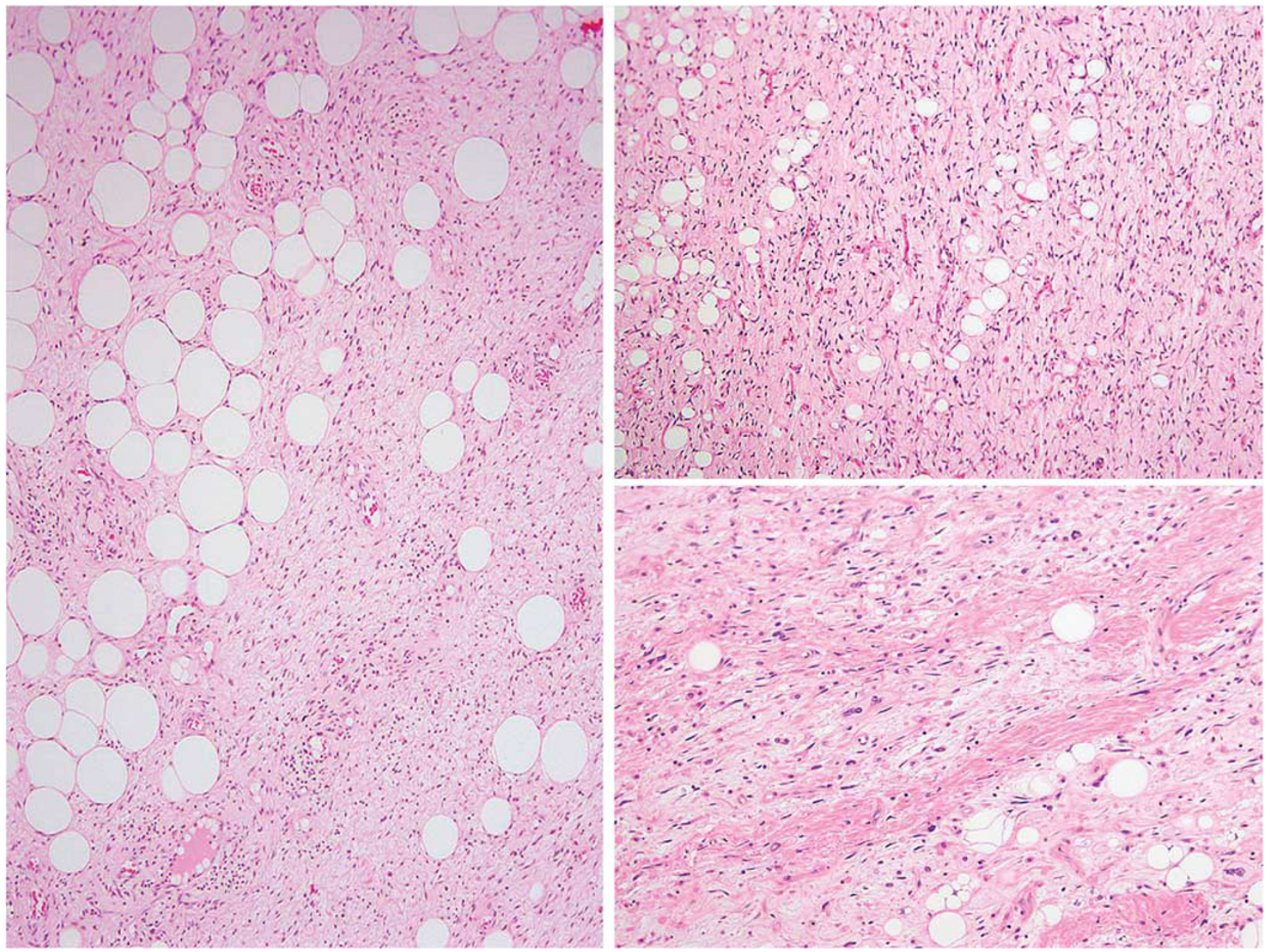

Figure 6 Spindle cell liposarcoma. The relative proportions of adipocytes and spindle cells is quite variable. Occasional cases may contain refractile collagen bundles similar to those in spindle cell lipoma (top right). Note that the spindle cells show at least focal nuclear atypia (lower right).

recently, ${ }^{30-33}$ probably because prior outdated concepts of histogenesis essentially excluded this possibility. In fact it seems that these lesions are not so rare (but may formerly have been mislabeled as myxoid chondrosarcoma or as an obscure metastasis) since, following publication of a relatively small series in early 1997, we have now seen over 400 additional examples, suggesting that pathologists are showing greater willingness to propose this diagnosis. These tumors affect all age groups but are most common before the age of 50; a significant subset (perhaps 10\%) occur in young children. Limbs (including hands and feet) are the commonest site and, while most cases are subcutaneous, up to $35 \%$ are intramuscular or subfascial. As with their salivary gland counterparts, around $15-20 \%$ recur locally and experience has shown that $10-15 \%$ ultimately metastasize, albeit most of those show cytologically atypical features (see below). Given the relative rarity of epithelial malignancies in children, myoepithelial carcinomas appear to be disproportionately frequent in this age group and are often very aggressive. $^{33}$

Histologically, myoepithelial lesions in soft tissue show the same broad spectrum as in salivary gland (Figure 9). The only (questionably valid) distinction between mixed tumor and myoepithelioma is the presence of a ductal component, which is identified in $15-20 \%$ of cases. The relative proportions of the myxoid/chondromyxoid tissue and epithelial/ myoepithelial components are very variable; around 10-15\% show overt chondro-osseous differentiation and rare examples show adipocytic differentiation. Occasional cases, as in salivary gland lesions, show transition to frank carcinoma or sarcoma, but the more usual clues to aggressive potential are nuclear atypia or prominent nucleoli. Mitotic rate and the character of the margin do not predict outcome. 

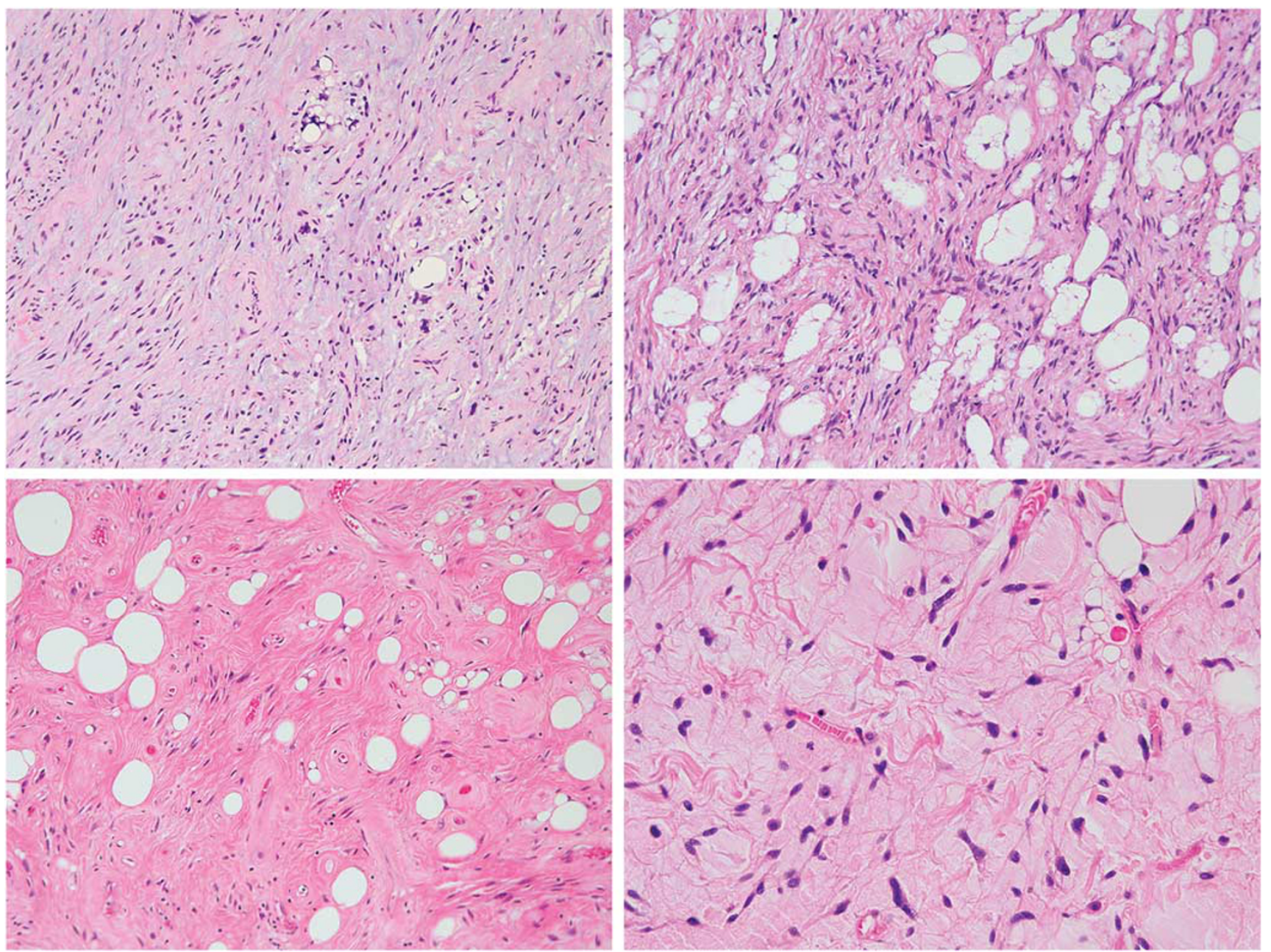

Figure 7 Spindle cell liposarcoma. Note the scattered lipoblasts, which may vary in number, as well as the mild nuclear atypia and hyperchromasia in spindle cells.

Immunohistochemically (Figure 10), most but not all cases are positive for keratin, along with S-100 protein in almost $90 \%$ or GFAP in $\sim 45 \% .{ }^{32}$ Calponin stains most cases, while EMA stains $60 \%$ and SMA is positive in only $20-25 \%$. p63 positivity is quite infrequent. Around $40-50 \%$ of myoepithelial carcinomas arising in soft tissue show loss of INI-1 expression, ${ }^{34}$ possibly due to chromosomal rearrangement or loss on 22q (see below). Consistent S-100 positivity allows distinction from most metastatic carcinomas (except perhaps those of breast) and myxoid chondrosarcoma is excluded by keratin positivity, the greater morphological heterogeneity, frequently very epithelial-like cytomorphology and the presence of ducts in some cases.

Parachordoma ${ }^{35-37}$ is an enigmatic neoplasm, which has not become well-established as an 'entity'. Despite its partial morphologic overlap with chordoma, it shows important topographic, clinical and immunohistochemical differences from the latter. By contrast, however, it is essentially indistinguishable from myoepithelioma/mixed tumor other than in the minor fact that the tumor cell cytoplasm is often notably vacuolated ${ }^{32}$ and, in the current WHO Classification, it is regarded as a variant of myoepithelioma. By contrast, extra-axial examples of chordoma, showing typical chordoma morphology and brachury immunopositivity, have now been convincingly demonstrated. ${ }^{38}$ Ectomesenchymal chondromyxoid tumor, ${ }^{39}$ which is most common in the tongue but may also occur elsewhere in the oral cavity, also appears to be a variant of myoepithelioma.

Recently, it has been demonstrated that almost $50 \%$ of soft tissue myoepithelial neoplasms show EWSR1 gene rearrangement, ${ }^{40}$ most often in malignant lesions as well as cases occurring in children and young adults. Furthermore, these data suggest that there may be a correlation between the specific type of gene fusion and distinct morphological subsets (most notably EWSR1-POU5F1 in lesions with clear cell morphology). ${ }^{40}$ Interestingly, 

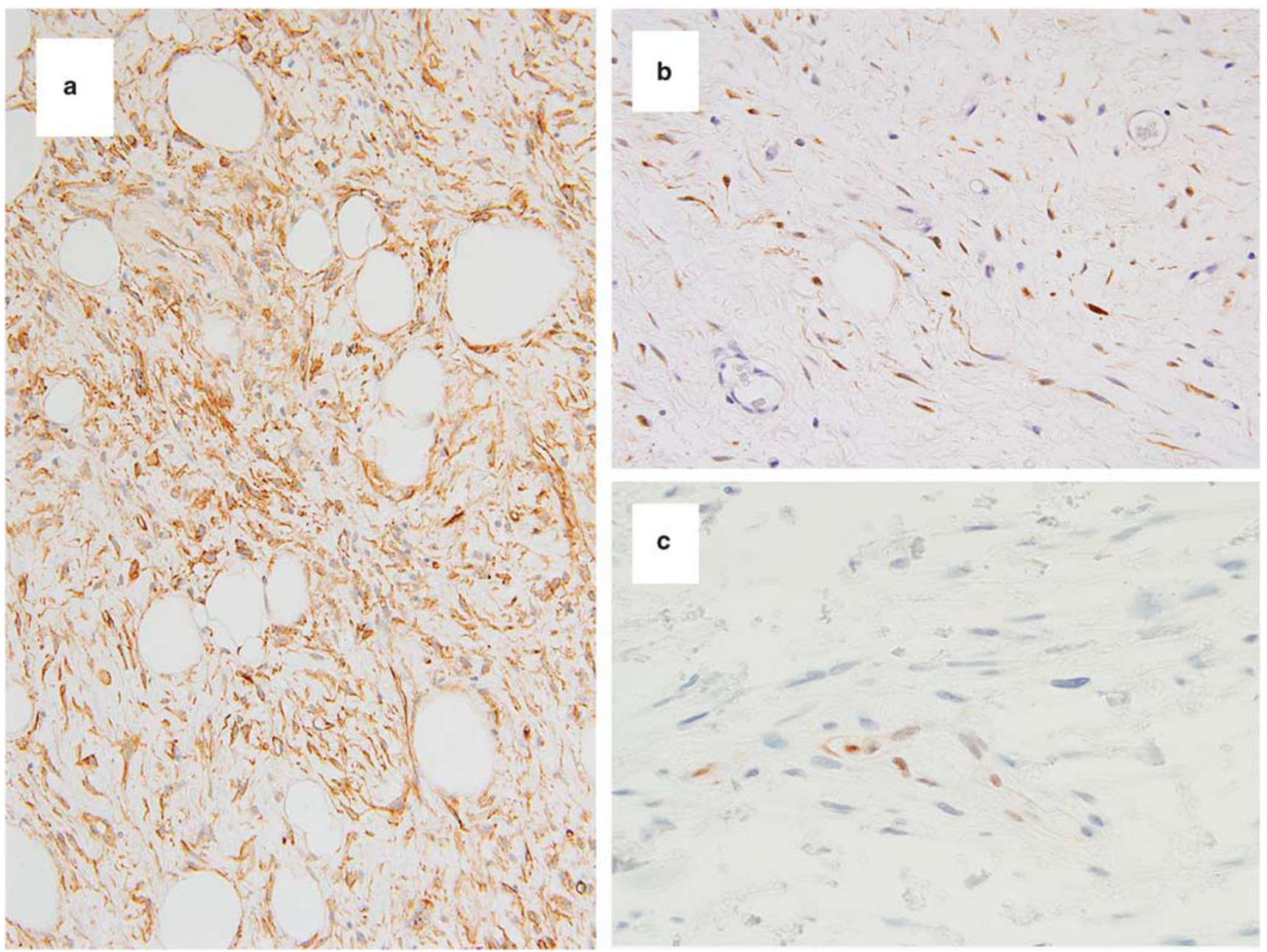

Figure 8 Spindle cell liposarcoma. The spindle cells in these lesions commonly express CD34 (left; a) and around 30\% of cases show nuclear positivity for S-100 protein in the spindle cell component (top right; b). Similar to spindle cell lipoma, these lesions often show loss of $\mathrm{Rb}-$ note that staining is retained in endothelial cells and inflammatory cells (lower right; c).

the morphologically distinctive syncytial variant of cutaneous myoepithelioma, which is most often positive for EMA and S-100 protein, also shows quite consistent EWSR1 rearrangement. ${ }^{41}$ By contrast, benign lesions showing ductal differentiation ('mixed tumors') frequently show PLAG1 gene rearrangement, ${ }^{42}$ similar to their salivary gland counterparts.

\section{Spindle cell/sclerosing rhabdomyosarcoma}

Rhabdomyosarcoma falls into three main groupsembryonal, alveolar and pleomorphic-and, in general terms, the first two groups occur mainly in children, while pure pleomorphic lesions occur almost exclusively in adults. Rhabdomyosarcoma in children occurs principally before the age of 10 years, with a peak before the age of 4 and shows a moderate male predominance. Commonest sites are the head and neck region (including orbit and meninges), followed by the genitourinary tract, then followed by the limbs and then trunk. As a general rule, embryonal lesions affect somewhat younger patients than the alveolar type and limb tumors are much more commonly alveolar than embryonal. By virtue of the anatomically awkward sites of predilection, most childhood examples of rhabdomyosarcoma are not amenable to complete excision, hence the drive towards effective radiotherapy and chemotherapy over the past 20 years. Overall 5-year survival figures now approach $60-70 \%$ and almost $50 \%$ of all childhood rhabdomyosarcomas are now said to be cured, which is a remarkable advance from the position just 25 years ago. The botryoid variant of embryonal rhabdomyosarcoma has an especially excellent prognosis (at least in children), while the presence of an even focal alveolar pattern confers a diminished survival probability. Relapse 

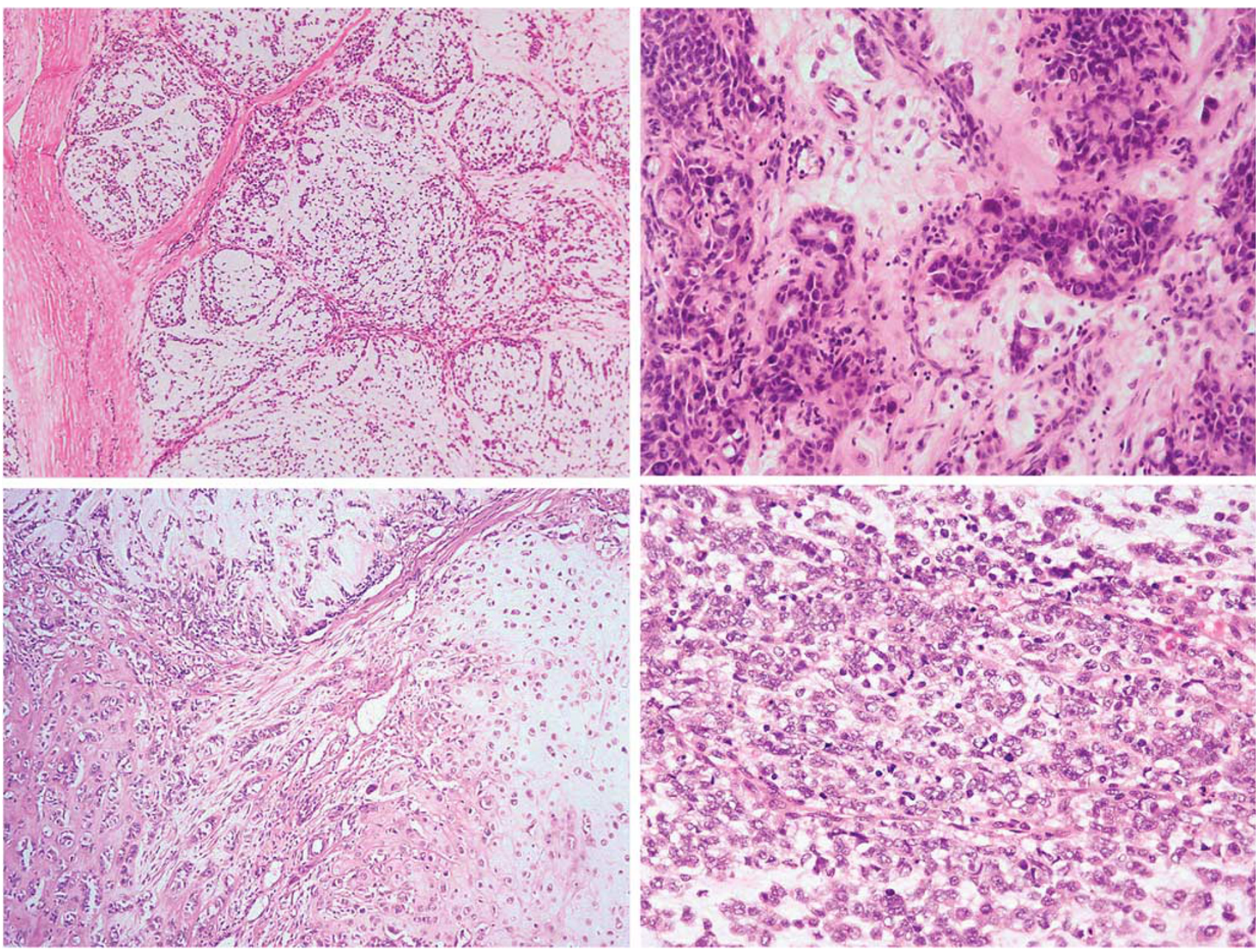

Figure 9 Myoepithelial tumors of soft tissue. These lesions show significant morphological heterogeneity, quite often closely resembling extraskeletal myxoid chondrosarcoma (top left), sometimes closely resembling mixed tumor of salivary gland (lower left) and in around 15-20\% of cases showing ductal differentiation (top right). Myoepithelial carcinomas of soft tissue usually show frankly malignant cytology (lower right).

after treatment in pediatric rhabdomyosarcoma represents a poor prognostic sign.

By contrast, rhabdomyosarcoma in adults predominantly arises in the limbs irrespective of histological type, appears to be somewhat more chemo-insensitive and has a 5-year survival probability of only around $40-50 \%$. In this age group, the pleomorphic subtype significantly outnumbers embryonal and alveolar lesions, although the latter do occur. Alveolar rhabdomyosarcomas in older adults most often arise in the head and neck region, especially the sinonasal tract. As a proportion of the whole, adult cases account for no more than $10 \%$.

A distinctive variant which, until recently, has been classified in the embryonal category is spindle cell rhabdomyosarcoma. The spindle cell variant of rhabdomyosarcoma was first recognized in the early $1990 \mathrm{~s}$ and was thought to occur principally in children and adolescents in the paratesticular region. ${ }^{43,44}$ Such lesions in young patients have been shown to have an extremely good prognosis with a 5 -year survival of greater than $90 \%$. Similar lesions in adults were first described in $1998,{ }^{45}$ and subsequent experience has shown that, in older patients, these lesions occur mainly in the third and fourth decades and show a striking predilection for the head and neck region, at which site it is difficult to obtain wide surgical margins. ${ }^{46}$ These tumors appear to be significantly more aggressive in adults. In either age group, these tumors are most often characterized by a fascicular (or less often storiform) proliferation of spindle-shaped cells with palely eosinophilic or amphophilic cytoplasm, admixed with which there are usually small numbers of brightly eosinophilic spindled or polygonal rhabdomyoblasts (Figure 11). Areas with conventional embryonal or alveolar features are generally not seen. Some cases show focally sclerosing 


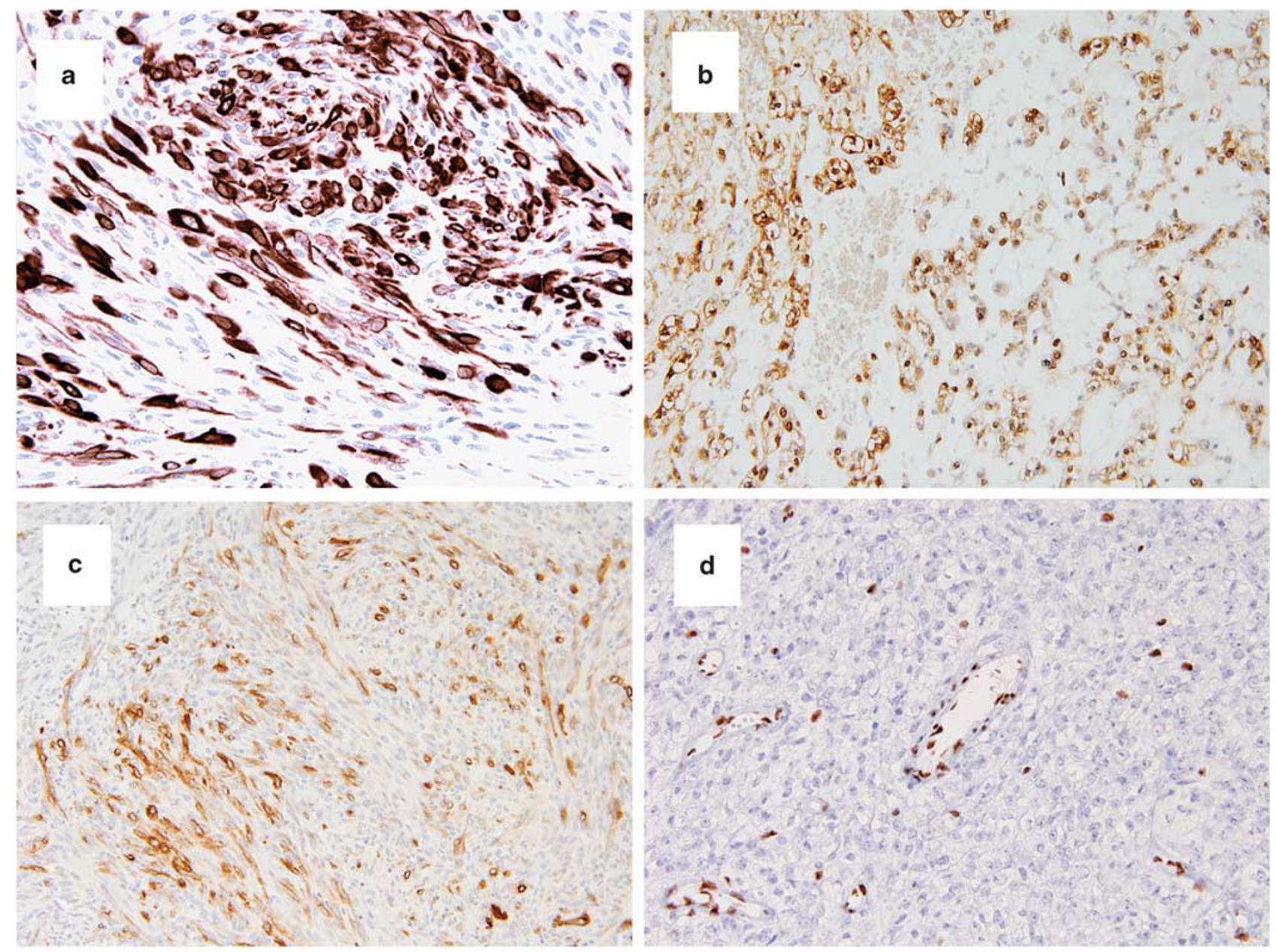

Figure 10 Myoepithelial tumors of soft tissue. The majority of cases show convincing positivity for keratin (top left; a), along with positivity for S-100 protein in around 90\% of cases (top right; b). Staining for EMA is somewhat less consistent (lower left; c). Loss of INI1 expression is seen in around $40-50 \%$ of myoepithelial carcinomas in soft tissue (lower right; d).

pseudovascular features, suggesting a close relationship with the sclerosing variant of rhabdomyosarcoma, as discussed below. To date, there have been no genetic data that would support a relationship between these tumors and either the embryonal or alveolar variants of rhabdomyosarcoma-in particular, there are no evident deletions on $11 p$, as seen in embryonal tumors. In truth, these lesions seem to have been co-classified with the embryonal variant mainly on the basis of their good prognosis and, in the new WHO classification, ${ }^{11}$ spindle cell and sclerosing rhabdomyosarcomas have been co-classified as a new distinct subset of rhabdomyosarcomas. Most recently, rearrangements of NCOA2 have been identified in spindle cell rhabdomyosarcomas arising in infancy, ${ }^{47}$ but data in adult cases and in sclerosing lesions are lacking as yet.

Sclerosing rhabdomyosarcoma, ${ }^{48-51}$ also quite recently recognized, may arise in either adults or children and is commonest in the limbs and head and neck region. These tumors are composed mainly of primitive-looking spindle, ovoid or round cells, often associated with prominent pseudovascular clefts, set in a prominent hyaline collagenous stroma (Figure 11). Hyalinization may be so prominent as to mimic osteosarcoma. Small foci of obvious rhabdomyoblastic differentiation may be evident. Some cases show areas indistinguishable from spindle cell rhabdomyosarcoma, in keeping with these being morphologic variations of a single tumor type. Additional genetic or molecular data in the future may help to support or refute this.

Differential diagnosis of spindle cell rhabdomyosarcoma includes principally other fascicular spindle cell sarcomas and the only truly reliable means to achieve this distinction in paraffin-embedded material (and in the absence of obvious morphologic evidence of rhabdomyoblastic differentiation) is by immunohistochemical demonstration of myf-4 or Myo-D positivity in a significant proportion of tumor cells, as muscle actin, desmin (Figure 12a) and SMA are not discriminatory. In my experience, myf-4 is generally the more useful and reliable marker (Figure 12b). MPNST with heterologous 

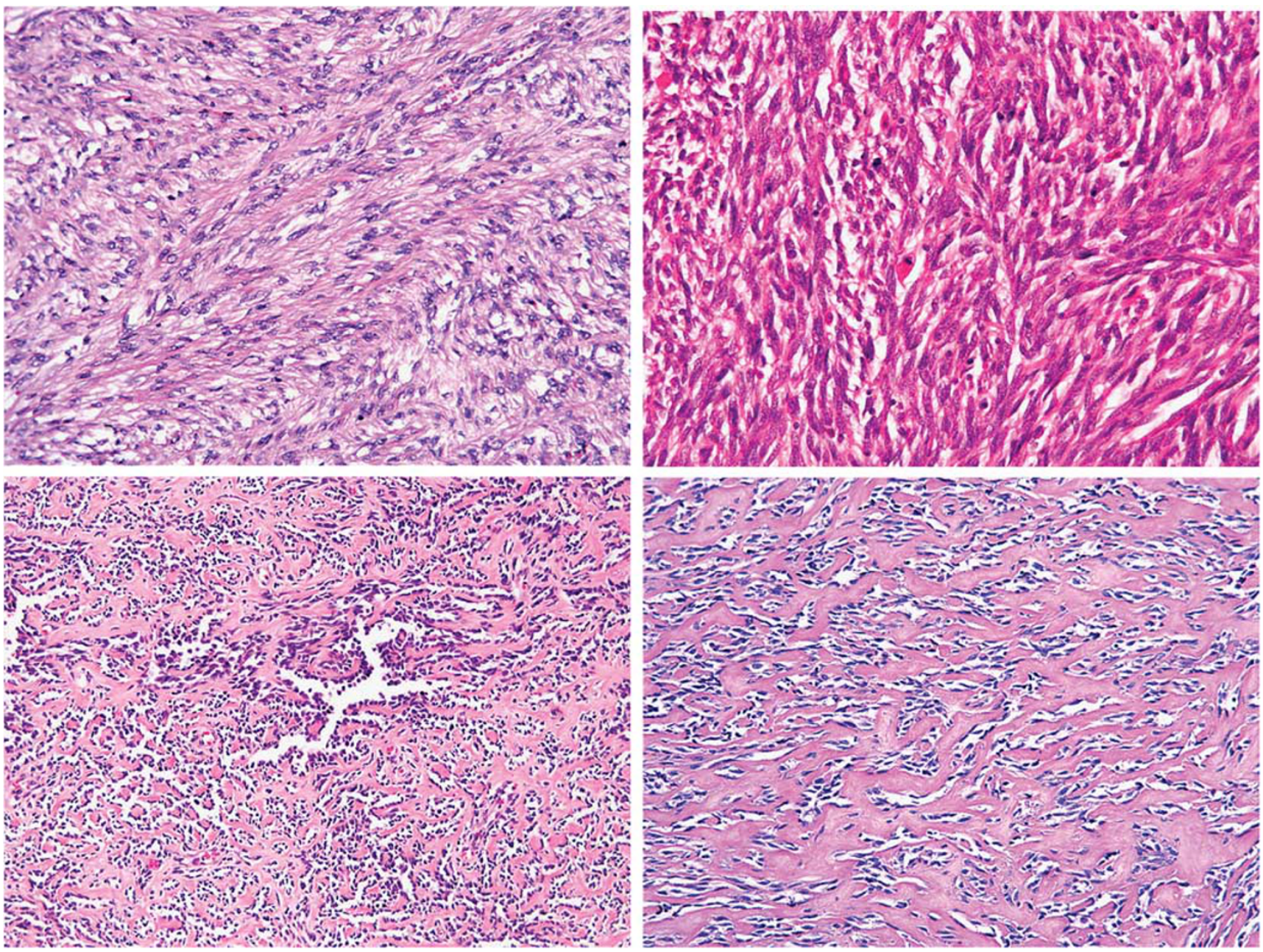

Figure 11 Spindle cell/sclerosing rhabdomyosarcoma. Spindle cell rhabdomyosarcomas have a fascicular growth pattern, easily mistaken for other sarcoma types (top left) but may show readily discernible eosinophilic rhabdomyoblasts in areas (top right). The sclerosing variant commonly has a pseudovascular growth pattern (lower left), but consists of spindle cells with similar morphology to those in the spindle cell variant, separated by a hyaline collagenous stroma (lower right).

rhabdomyoblastic differentiation (malignant Triton tumor) may also enter the differential diagnosis. However, many such lesions are either associated with NF-1, arise from a demonstrable nerve or show areas of conventional MPNST. In most Triton tumors, the tumor cells showing rhabdomyoblastic differentiation constitute a relatively small proportion of the overall neoplasm. Rare cases may need to be distinguished from spindle cell carcinoma or melanoma.

Differential diagnosis of sclerosing rhabdomyosarcoma, at least in my experience, includes most often either angiosarcoma (because of the prominent pseudovascular pattern) or else, sometimes, alveolar rhabdomyosarcoma. Although the former is easily distinguished on immunohistochemical grounds, the latter may require molecular genetic testing to check for the presence of FOXO1 gene rearrangement. Furthermore, true alveolar rhabdomyosarco- mas tend more often to show rounded rather than elongated slit-like spaces and there are frequently wreath-like multinucleate giant cells.

\section{Conclusion}

Hopefully, this brief overview has helped to confirm the importance of the ongoing identification or better recognition of distinct and previously unrecognized types of soft tissue tumor. It is clear that this process helps not only in facilitating better diagnosis but also has impact in terms of biologic understanding and rational classification schemes. Remarkably, it seems that this process will continue for the foreseeable future-even in the past 2 years additional 'new' entities have emerged, each of which is associated with specific molecular genetic aberrations-pseudomyogenic (epithelioid sarcoma- 

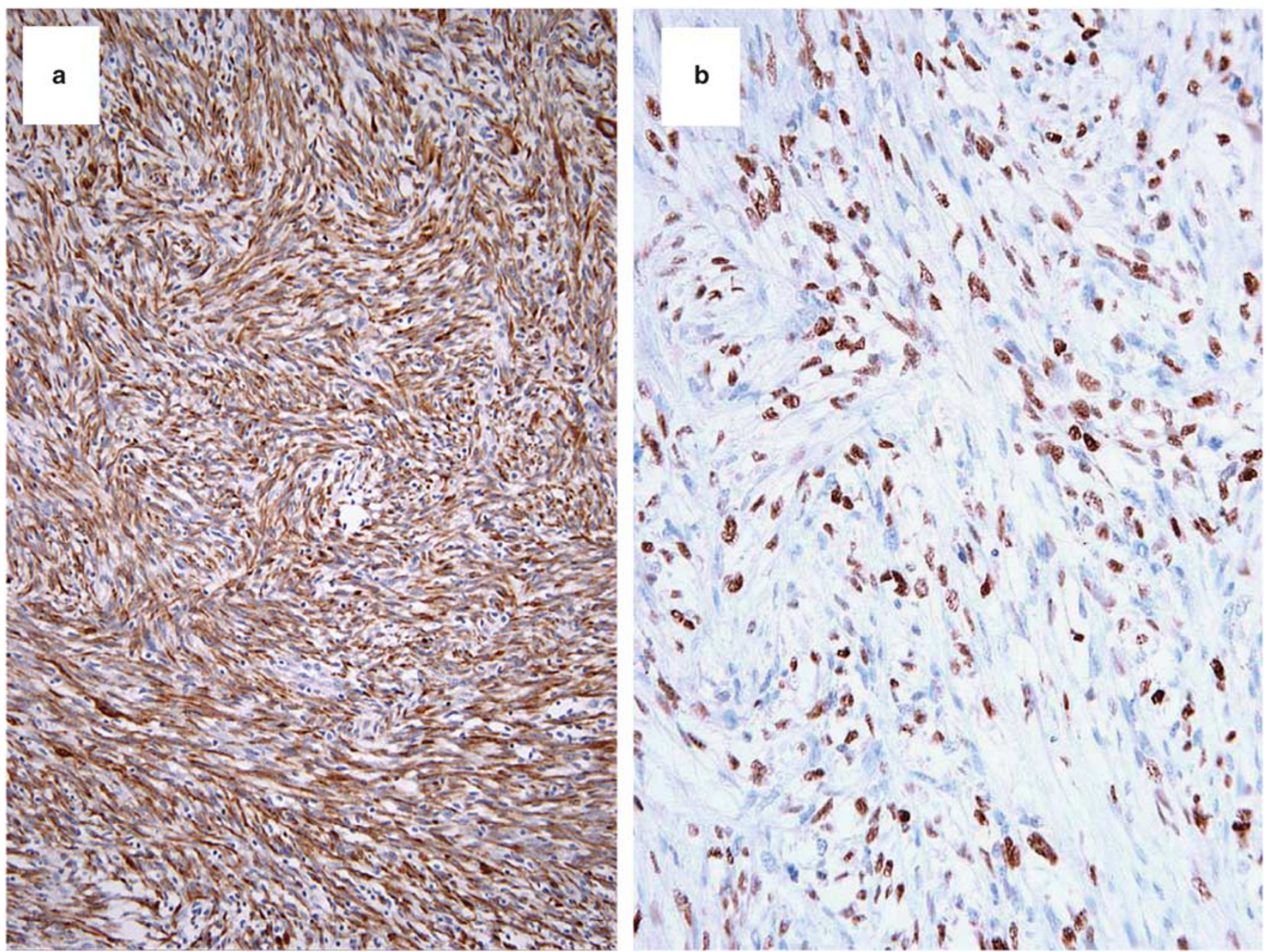

Figure 12 Spindle cell rhabdomyosarcoma. Note the generally diffuse positivity for desmin (a), as well as the multifocal nuclear positivity for myf-4 (myogenin) (b), which is generally the most reliable myogenic transcription factor for immunohistochemical purposes.

like) hemangioendothelioma, ${ }^{52,53}$ round cell sarcomas with CIC-DUX4 fusion ${ }^{54}$ and angiofibroma of soft tissue. ${ }^{55,56}$ It is especially impressive to note that morphologic recognition of these lesions has typically preceded molecular genetic characterization-in other words, morphology remains remarkably reproducible and cost-effective. As this ongoing characterization of soft tissue tumors continues, it seems that this work will help to guide the potential development of rational new therapies, while ensuring that we as pathologists render ever more reliable and reproducible diagnoses.

\section{Disclosure/conflict of interest}

The author declares no conflict of interest.

\section{References}

1 Fletcher CDM. Benign fibrous histiocytoma of subcutaneous and deep soft tissue: a clinicopathologic analysis of 21 cases. Am J Surg Pathol 1990;14:801-809.
2 Gleason BC, Fletcher CDM. Deep 'benign' fibrous histiocytoma: clinicopathologic analysis of 69 cases of a rare tumor indicating occasional metastatic potential. Am J Surg Pathol 2008;32:354-362.

3 Marshall-Taylor C, Fanburg-Smith JC. Hemosiderotic fibrohistiocytic lipomatous lesion: ten cases of a previously undescribed fatty lesion of the foot/ankle. Mod Pathol 2000;13:1192-1199.

4 Browne TJ, Fletcher CDM. Haemosiderotic fibrolipomatous tumor (so-called haemosiderotic fibrohistiocytic lipomatous tumour): analysis of 13 new cases in support of a distinct entity. Histopathology 2006;48: 453-461.

5 Folpe AL, Weiss SW. Pleomorphic hyalinizing angiectatic tumor: analysis of 41 cases supporting evolution from a distinctive precursor lesion. Am J Surg Pathol 2004;28:1417-1425.

6 Wettach GR, Boyd LJ, Lawce HJ, et al. Cytogenetic analysis of a hemosiderotic fibrolipomatous tumor. Cancer Genet Cytogenet 2008;15:140-143.

7 Hallor KH, Sciot R, Staaf J, et al. Two genetic pathways, $\mathrm{t}(1 ; 10)$ and amplification of $3 \mathrm{p} 11-12$, in myxoinflammatory fibroblastic sarcoma, haemosiderotic fibrolipo- 
matous tumour, and morphologically similar lesions. J Pathol 2009;217:716-727.

8 Antonescu CR, Zhang L, Nielsen GP, et al. Consistent $t(1 ; 10)$ with rearrangements of TGFBR3 and MGEA5 in both myxoinflammatory fibroblastic sarcoma and hemosiderotic fibrolipomatous tumor. Genes Chromos Cancer 2011;50:757-784.

9 Mohajeri A, Kindblom LG, Sumathi VP, et al. SNP array and FISH findings in two pleomorphic hyalinizing angiectatic tumors. Cancer Genet 2012;205: 673-676.

10 Bonetti F, Pea M, Martignoni G, et al. PEC and sugar. Am J Surg Pathol 1992;16:307-308.

11 Fletcher CDM, Bridge JA, Hogendoorn PCW, Mertens F(eds).World Health Organisation Classification of Tumours. Pathology and Genetics of Tumours of Soft Tissue and Bone, 4th edn. IARC: Lyon, 2013.

12 Hornick JL, Fletcher CDM. PEComa: what do we know so far? Histopathology 2006;48:75-82.

13 Folpe AL, Mentzel T, Lehr HA, et al. Perivascular epithelioid cell neoplasms of soft tissue and gynecologic origin: a clinicopathologic study of 25 cases and review of the literature. Am J Surg Pathol 2005;29: 1558-1575.

14 Folpe AL, Kwiatkowski DJ. Perivascular epithelioid cell neoplasms: pathology and pathogenesis. Hum Pathol 2010;41:1-15.

15 Hornick JL, Fletcher CDM. Sclerosing PEComa: clinicopathologic analysis of a distinctive variant with a predilection for the retroperitoneum. Am J Surg Pathol 2008;32:493-501.

16 Mentzel T, Reisshauer S, Rütten A, et al. Cutaneous clear cell myomelanocytic tumour: a new member of the growing family of perivascular epithelioid cell tumours (PEComas). Clinicopathological and immunohistochemical analysis of seven cases. Histopathology 2005;46:498-504.

17 Liegl B, Hornick JL, Fletcher CDM. Primary cutaneous PEComa: distinctive clear cell lesions of skin. Am J Surg Pathol 2008;32:608-614.

18 Bleeker JS, Quevedo JF, Folpe AL. 'Malignant' perivascular epithelioid cell neoplasm: risk stratification and treatment strategies. Sarcoma 2012;2012: 541626.

19 Rao Q, Cheng L, Xia QY, et al. Cathepsin K expression in a wide spectrum of perivascular epithelioid cell neoplasms: a clinicopathological study emphasising extrarenal PEComas. Histopathology 2013;62:642-650.

20 Argani P, Aulmann S, Illei PB, et al. A distinctive subset of PEComas harbors TFE3 gene fusions. Am J Surg Pathol 2010;34:1395-1406.

21 Kenerson H, Folpe AL, Takayama TK, et al. Activation of the mTOR pathway in sporadic angiomyolipomas and other perivascular epithelioid cell neoplasms. Hum Pathol 2007;38:1361-1371.

22 Martignoni G, Pea M, Reghellin D, et al. Molecular pathology of lymphangio-leiomyomatosis and other perivascular epithelioid cell tumors. Arch Pathol Lab Med 2010;134:33-40.

23 Malinowska I, Kwiatkowski D, Weiss S, et al. Perivascular epithelioid cell tumors harboring TFE3 gene rearrangements lack the TSC2 alterations characteristic of conventional PEComas: further evidence for biologic distinction. Am J Surg Pathol 2012;36:783-784.

24 Wagner AJ, Malinowska-Kolodziej I, Morgan JA, et al. Clinical activity of mTOR inhibition with sirolimus in malignant perivascular epithelioid cell tumors: target- ing the pathogenic activation of mTORC1 in tumors. J Clin Oncol 2010;28:835-840.

25 Dickson MA, Schwartz GK, Antonescu CR, et al. Extrarenal perivascular epithelioid cell tumors (PEComas) respond to mTOR inhibition: clinical and molecular correlates. Int J Cancer 2013;132:1711-1717.

26 Dei Tos AP, Mentzel T, Newman PL, et al. Spindle cell liposarcoma: a hitherto unrecognized variant of liposarcoma: analysis of six cases. Am J Surg Pathol 1994;18:913-921.

27 Nascimento AF, Fletcher CDM. Spindle cell liposarcoma/atypical lipomatous tumour: a clinicopathologic study of 120 cases. Mod Pathol 2005;18:19A (Abstract).

28 Italiano A, Chambonniere ML, Attias R, et al. Monosomy 7 and absence of 12q amplification in two cases of spindle cell liposarcoma. Cancer Genet Cytogenet 2008;184:99-104.

29 Mentzel T, Palmedo G, Kuhnen C. Well-differentiated spindle cell liposarcoma ('atypical spindle cell lipomatous tumor') does not belong to the spectrum of atypical lipomatous tumour but has a close relationship to spindle cell lipoma: clinicopathologic immunohistochemical and molecular analysis of 6 cases. Mod Pathol 2010;23:729-736.

30 Kilpatrick SE, Hitchcock MG, Kraus MD, et al. Mixed tumors and myoepitheliomas of soft tissue: a clinicopathologic study of 19 cases with a unifying concept. Am J Surg Pathol 1997;21:13-22.

31 Michal M, Miettinen M. Myoepitheliomas of the skin and soft tissues. Report of 12 cases. Virchows Arch 1999;434:393-400.

32 Hornick JL, Fletcher CDM. Myoepithelial tumors of soft tissue: a clinicopathologic and immunohistochemical study of 101 cases with evaluation of prognostic parameters. Am J Surg Pathol 2003;27:1183-1198.

33 Gleason BC, Fletcher CDM. Myoepithelial carcinoma of soft tissue in children: an aggressive neoplasm analyzed in a series of 29 cases. Am J Surg Pathol 2007; 31:1813-1824.

34 Hollmann TJ, Hornick JL. INI1-deficient tumors: diagnostic features and molecular genetics. Am J Surg Pathol 2011;35:e47-e63.

35 Dabska M. Parachordoma. A new clinicopathologic entity. Cancer 1997;40:1586-1592.

36 Fisher C, Miettinen M. Parachordoma: a clinicopathologic and immunohistochemical study of four cases of an unusual soft tissue neoplasm. Ann Diagn Pathol 1997;1:3-10.

37 Folpe AL, Agoff SN, Willis J, et al. Parachordoma is immunohistochemically and cytogenetically distinct from axial chordoma and extraskeletal myxoid chondrosarcoma. Am J Surg Pathol 1999;23:1059-1067.

38 Tirabosco R, Mangham DC, Rosenberg AE, et al. Brachyury expression in extra-axial skeletal and soft tissue chordomas: a marker that distinguishes chordoma from mixed tumor/myoepithelioma/parachordoma in soft tissue. Am J Surg Pathol 2008;32:572-580.

39 Smith BC, Ellis GL, Meis-Kindblom JM, et al. Ectomesenchymal chondromyxoid tumor of the anterior tongue. Nineteen cases of a new clinicopathologic entity. Am J Surg Pathol 1995;19:519-530.

40 Antonescu CR, Zhang L, Chang NE, et al. EWSR1POU5F1 fusion in soft tissue myoepithelial tumors. A molecular analysis of sixty-six cases, including soft tissue, bone, and visceral lesions, showing common involvement of the EWSR1 gene. Genes Chromos Cancer 2010;49:1114-1124. 
41 Jo VY, Antonescu CR, Zhang L, et al. Cutaneous syncytial myoepithelioma: clinicopathologic characterization in a series of 38 cases. Am J Surg Pathol 2013;37:710-718.

42 Antonescu CR, Zhang L, Shao SY, et al. Frequent PLAG1 gene rearrangements in skin and soft tissue myoepithelioma with ductal differentiation. Genes Chromos Cancer 2013;52:675-682.

43 Cavazzana AO, Schmidt D, Ninfo V, et al. Spindle cell rhabdomyosarcoma. A prognostically favorable variant of rhabdomyosarcoma. Am J Surg Pathol 1992;16: 229-235.

44 Leuschner I, Newton WA Jr., Schmidt D, et al. Spindle cell variants of embryonal rhabdomyosarcoma in the paratesticular region. A report of the Intergroup Rhabdomyosarcoma Study. Am J Surg Pathol 1993; 17:221-230.

45 Rubin BP, Hasserjian RP, Singer S, et al. Spindle cell rhabdomyosarcoma (so-called) in adults: report of two cases with emphasis on differential diagnosis. Am J Surg Pathol 1998;22:459-464.

46 Nascimento AF, Fletcher CDM. Spindle cell rhabdomyosarcoma in adults. Am J Surg Pathol 2005;29: 1106-1113.

47 Mosquera JM, Sboner A, Zhang L, et al. Recurrent NCOA2 gene rearrangement in congenital/infantile spindle cell rhabdomyosarcoma. Genes Chromos Cancer 2013;52:538-559.

48 Mentzel T, Katenkamp D. Sclerosing pseudovascular rhabdomyosarcoma in adults. Clinicopathological and immunohistochemical analysis of three cases. Virchows Arch 2000;436:305-311.

49 Folpe AL, McKenney JK, Bridge JA, et al. Sclerosing rhabdomyosarcoma in adults: report of four cases of a hyalinizing, matrix-rich variant of rhabdomyosarcoma that may be confused with osteosarcoma, chondrosarcoma, or angiosarcoma. Am J Surg Pathol 2002;26: 1175-1183.

50 Chiles MC, Parham DM, Qualman SJ, et al. Sclerosing rhabdomyosarcomas in children and adolescents: a clinicopathologic review of 13 cases from the Intergroup Rhabdomyosarcoma Study Group and Children's Oncology Group. Pediatr Dev Pathol 2004;7: 583-594.

51 Wang J, Tu X, Sheng W. Sclerosing rhabdomyosarcoma: a clinicopathologic and immunohistochemical study of five cases. Am J Clin Pathol 2008;129: 410-415.

52 Hornick JL, Fletcher CD. Pseudomyogenic hemangioendothelioma: a distinctive, often multicentric tumor with indolent behavior. Am J Surg Pathol 2011; 35:190-201.

53 Trombetta D, Magnusson L, von Steyern FV, et al. Translocation $\mathrm{t}(7 ; 19)(\mathrm{q} 22 ; \mathrm{q} 13)$-a recurrent chromosome aberration in pseudomyogenic hemangioendothelioma? Cancer Genet 2011;204:211-215.

54 Italiano A, Sung YS, Zhang L, et al. High prevalence of CIC fusion with double-homeobox (DUX4) transcription factors in EWSR1-negative undifferentiated small blue round cell sarcomas. Genes Chromos Cancer 2012;51:207-218.

55 Mariño-Enriquez A, Fletcher CD. Angiofibroma of soft tissue: clinicopathologic characterization of a distinctive benign fibrovascular neoplasm in a series of 37 cases. Am J Surg Pathol 2012;36:500-508.

56 Jin Y, Möller E, Nord KH, et al. Fusion of the AHRR and NCOA2 genes through a recurrent translocation $\mathrm{t}(5 ; 8)(\mathrm{p} 15 ; \mathrm{q} 13)$ in soft tissue angiofibroma results in upregulation of aryl hydrocarbon receptor target genes. Genes Chromos Cancer 2012;51:510-520. 